\title{
Urban Mobility and Database Allied to Environmental Regeneration of a University Campus
}

XXIV International Conference of the Iberoamerican Society

of Digital Graphics Medellin | Colombia

\author{
Camila Poeta Mangrich \\ Universidade Federal de Santa Catarina | Brasil | camila.poeta@ufsc.br \\ Renato Luiz Martins de Almeida \\ Universidade Federal de Santa Catarina | Brasil | arq.renatomartins@gmail.com \\ Gabriela Peglow Harthmann \\ Universidade Federal de Santa Catarina | Brasil | gabriela.harthmann@grad.ufsc.br \\ José Ripper Kós \\ Universidade Federal de Santa Catarina | Brasil | jose.kos@ufsc.br
}

\begin{abstract}
This study departs from the data exploration of the people dynamics within a university campus to foster solutions of sustainable mobility and environmental regeneration. The research has dealt with a critical challenge of guaranteeing the privacy of individuals' registration data, following the recommendations listed in the foreseen General Data Protection Law. While ensuring anonymity, the work aims to assess the contribution of databases as infrastructures that can convey relevant knowledge beyond scientific research and to guide public management to the trends advocated for the future of universities.
\end{abstract}

Keywords: University campus; Mobility; Database visualization; Sustainability.

\section{INTRODUÇÃO}

Cada novo evento que extrapola as fronteiras de um determinado território torna notáveis as questões socioambientais como dinâmicas e conectadas. Destes sistemas interligados urge a busca por soluções igualmente integradas entre as diversas áreas do conhecimento e escalas territoriais. Para Grimm (2008), as cidades representam microcosmos dos tipos de mudanças que estão ocorrendo globalmente, tornando-os casos de teste informativos para entender a dinâmica do sistema socioecológico e as respostas à mudança.

O ano de 2020, embalsamado pela pandemia da COVID19 , catalisou temáticas que vinham sendo discutidas a passos lentos pela gestão pública. O controle da densidade demográfica, do incremento da poluição atmosférica e da redução desenfreada da cobertura vegetal na dispersão da malha urbana tornou-se ainda mais urgente. As ciências do urbanismo, saúde pública e tecnologia da informação se aproximaram para integrar dados e orientar os gestores na tomada de decisões em uma crise prenunciada na escala global.

Neste cenário, a promoção do distanciamento social como medida de controle da contaminação, difundido pelo mote "fique em casa", resultou no esvaziamento das ruas e evidenciou a necessidade de conhecer a relação dos indivíduos com seus habitats. As moradias, transformadas em escritórios, escolas e outros serviços, tiveram que abrigar muitas das atividades cotidianas que as pessoas desempenham de maneira diluída no território urbano, reduzindo seus deslocamentos nas cidades ao estritamente tido como essencial em curtos trajetos. O que parecia novidade, porém, já vinha sendo defendido por diversos teóricos do urbanismo como maneira de reduzir os danos ambientais, otimizando o tráfego de motorizados e adequando as cidades à realidade da geração dos millenials, mais conectada e engajada.

A nova tipologia da cidade proposta combina planejamento descendente suave com emergência espontânea de contextos locais; é uma cidade emergindo como uma soma de assentamentos multifuncionais compactos e acessiveis, permeados por toda a natureza, sem formas fixas planejadas e ilimitadamente extensiveis, nas quais se pode sentir a urbanidade e a natureza (D'Acci, 2019, p. 4).

Trabalhando com o conceito de centralidades com benefícios igualmente distribuídos, D'Acci (2019) defende uma morfologia urbana onde as pessoas possam ter acesso fácil aos principais serviços diários, locais de trabalho e contato com a natureza em trajetos médios de 15 minutos de caminhada. Variáveis como esta estão sendo adotadas em cidades como Paris, Barcelona e Portland que, com o incentivo à mobilidade menos poluente e a redução do acesso de motorizados nos principais centros, buscam tornar-se mais caminháveis com trajetos que variam entre 10 e 20 minutos.

Em São Paulo, uma pesquisa realizada durante a pandemia da COVID-19 apontou, quanto ao transporte ativo, uma expectativa otimista no comportamento das pessoas ao término da crise sanitária, onde $38 \%$ dos entrevistados demonstraram intenção de se deslocar mais a pé e $20 \%$ pretendem usar mais a bicicleta no dia-a-dia 
(IBOPE 2020). Entretanto, o distanciamento físico entre as pessoas recomendado pela Organização Mundial de Saúde (OMS), de certa forma, vilanizou o transporte público, dada a precariedade e superlotação dos serviços oferecidos na maioria das metrópoles brasileiras. Entre os paulistanos, $26 \%$ pretendem usar menos o ônibus e $24 \%$ querem diminuir o uso de trem ou metrô nos deslocamentos cotidianos entre suas residências e locais de trabalho (IBOPE 2020).

O presente artigo traz esses conceitos para a realidade de um campus universitário, compreendendo seu território como uma centralidade importante dentro da cidade onde está implantado, conectado com inúmeras outras centralidades que extrapolam os limites governamentais. Destino diário de uma grande diversidade de pessoas, um campus universitário possui registros que o evidenciam como um lugar ideal para se propor mudanças de paradigmas de longo alcance. Assim, o objetivo deste estudo é demonstrar de que forma as dinâmicas de uma comunidade acadêmica podem estar entrelaçadas com as dinâmicas de diversas centralidades de uma região urbana. Para tal, propõe o uso do banco de dados da própria instituição como facilitador na busca de soluções e propostas aplicáveis em suas glebas e na rede territorial extra campus.

\section{CAMPUS UNIVERSITÁRIO COMO CENTRALIDADE}

Tradicionalmente criadas para abrigar atividades voltadas para o Ensino Superior, as universidades evoluíram ao longo dos séculos abrindo espaço gradualmente aos cientistas e pesquisadores, atividades ainda pouco difundidas na sociedade civil. Apesar de ter sua imagem predominantemente atrelada à presença dos estudantes, os campi são hoje locais de trabalho de milhares de pessoas que para lá se deslocam diariamente para cumprir sua jornada laboral essencialmente intelectual.

A imagem clichê da universidade faz parte de um grupo de estudiosos não-mundanos que preferem fazer seu trabalho em reclusão. Em profundo silêncio, são realizadas pesquisas sobre assuntos dos quais ninguém nunca ouviu falar, ou talvez nem se importe. Com base nessa imagem, o local ideal para uma universidade estaria em algum lugar de uma região remota, garantindo assim essas condições básicas de paz e reclusão (Zwaan, 2017, p. 125).

Questionando a localização física das universidades, Zwaan (2017) invoca, contudo, a importância da conectividade do espaço físico acadêmico com as atividades sociais do seu entorno para garantir a aplicabilidade imediata dos conhecimentos nela produzidos. O seu papel na área urbana em que se localiza é subestimado, embora muitas delas, mas especialmente as universidades, cooperem fortemente com outras organizações instaladas na mesma região (Sedlacek, 2013). O que as diferencia das demais é seu objetivo de fornecer um ambiente favorável ao aprendizado (Hajrasouliha, 2017) à totalidade da população. Para Chapman (2006), a mudança no perfil universitário está remodelando o campus por seus padrões de migração e mobilidade e pela multiplicidade de seus grupos socioeconômicos, étnicos e etários. A nova demografia estudantil, representada pelos millenials, tem exigido uma apropriação do campus universitário diversa das gerações anteriores, até então restrita a grupos elitizados da sociedade.
A tecnologia digital é uma parte natural da vida dos millenials. Sendo mais diversificados e mais conectados, eles tendem a aceitar diferenças nos outros com mais facilidade. Eles esperam mudanças no mundo e em suas vidas. Eles têm grandes expectativas em relação a seus ambientes educacional, cívico e de trabalho (Chapman, 2006, p. 102).

Diante de tamanha diversidade social e avanço tecnológico que paira hoje nas universidades, acrescido do cenário imposto pela pandemia do COVID-19, muito se questiona o papel da universidade do futuro (Barnett, 2012; Taylor, 2016; Zwaan 2017). Como centro educacional, diante da expansão das plataformas de ensino a distância, em que período da vida acadêmica a presença física no campus continuará essencial? Como local de ofício, com a disseminação do teletrabalho, para quem a ida à universidade seguirá indispensável? Para muitos acadêmicos, a execução de suas atividades de maneira remota simboliza uma grande perda, seja da oportunidade de trocas com seus pares nos corredores e caminhos internos do campus, seja da especificidade de infraestrutura compartilhada nos laboratórios universitários. Para Zwaan (2017), esse grupo de acadêmicos representa a sobrevivência do campus físico atuando em conjunto com a universidade digital. Cabe aos seus gestores planejar e executar a infraestrutura adequada que conecte as duas realidades, reconhecendo que as bases da universidade híbrida já estão em execução.

\section{INFRAESTRUTURA VIÁRIA}

A partir da compreensão da conectividade da universidade com as diversas centralidades urbanas, as políticas de acesso e deslocamento até o campus serão determinantes para a manutenção das atividades presenciais de maneira eficaz e segura. Dessa forma, quando se trata de mobilidade urbana, difícil desvincular diagnósticos e proposições da universidade com a realidade do seu entorno imediato. Contudo, um campus universitário não é uma cidade, um bairro ou um quarteirão, possui missões e governanças específicas e deve ter uma análise particular de sua comunidade (Hajrasouliha, 2017). O modo como os alunos, funcionários e professores se deslocam até a universidade é também de sua responsabilidade, se vista sob o ponto de vista da infraestrutura viária que o campus oferece internamente e, externamente, das parcerias que estabelece junto à gestão municipal e estadual na promoção do transporte público de qualidade. Além das diferenciações do território universitário em relação à cidade, uma atenção especial deve ser dada às dinâmicas dos estudantes em seus trajetos para além dos limites do campus. Eles fazem parte de um quadro demográfico diferente dos trabalhadores da universidade (Sedlacek, 2013; Zhou, 2016) seja pela faixa etária, condições de moradia, flexibilidade de horários, relações de trabalho e renda, entre outros fatores que podem influenciar, por exemplo, a promoção de modos de transporte mais sustentáveis nas suas viagens cotidianas.

Limites discretos entre a universidade e o bairro podem criar um campus isolado. Habitações inacessíveis podem fazer com que os alunos viajem longas distância. Um campus de baixa densidade, baixa qualidade de moradia, zoneamento inadequado, relacionamentos hostis com a cidade, reputação como uma "universidade da festa" e injustiça social também são ameaças em potencial para os campi das universidades (Hajrasouliha, 2017, p. 364). 
A citação acima, embora se refira originalmente às universidades norte-americanas, onde "quase todos os campi urbanos enfrentarem sérios impactos do tráfego de carros e da escassez de estacionamento" (Hajrasouliha, 2017), facilmente representa a realidade de muitas cidades cujo desenho urbano levou à dependência enraizada do uso individualizado do veículo motorizado. Consequências que vão além das questões ambientais, emissão de gases e uso da terra, a cultura carrocêntrica levou a fatores econômicos e psicológicos (D'Acci, 2019; Zhou, 2016) que se direcionados ao cotidiano do estudante universitário, levam a significativo impacto na sua produção acadêmica.

Sendo notórios os aspectos ambientais, urbanos e demográficos quanto à mobilidade, Zhou (2016) critica ainda a reduzida influência das políticas institucionais da universidade na escolha do modo de transporte de sua comunidade. Fatores como flexibilidade nos horários das aulas e demais atividades acadêmicas, incentivos variados para o uso do transporte ativo (a pé ou bicicleta) e negociações com as empresas de transporte público podem contribuir para a redução da presença do carro nas dependências do campus (Zhou, 2016). Ações simples e de baixo custo como estas, que reordenam a programação de horários de pico dos espaços acadêmicos, podem resultar na redução da demanda por estacionamentos e, por consequência, um uso mais amplo do espaço de ensino (Chapman, 2006).

\section{INFRAESTRUTURA DE DADOS}

Aliadas aos aspectos geográficos e organizacionais mencionados, as tecnologias de informação vêm despontando como infraestruturas digitais que formulam a paisagem digital das cidades (Morozov, 2019). Contudo, o uso desenfreado de dados pessoais na produção das ditas 'smart cities' tem gerado críticas quanto à privacidade dos usuários e o aumento da comercialização de suas informações. O debate sobre o uso indevido de dados por empresas e governos levou a uma revisão da legislação relativa à privacidade de dados em diversos países. No Brasil, com a consolidação da Lei Geral de Proteção de Dados (Lei Nº13.709, 2018), a anonimização é a única possibilidade de trabalhar com dados pessoais.

O anonimato é considerado um estado de privacidade (Westin, 1967). Para Warekar (2016), a ideia central do anonimato é garantir que a pessoa não seja identificada, alcançada e rastreada. Com os dados anonimizados, não é possivel identificar e distinguir um sujeito em um determinado grupo. A anonimização de bancos de dados semelhantes forneceria um recurso importante para a maioria das universidades para explorar esses dados para gestão e projetos de pesquisa. Ainda assim, o uso de dados, se gerenciados corretamente e garantindo a distinta anonimização dos usuários, pode funcionar como importante infraestrutura para a gestão urbana. Diversificados são os métodos para se obter as informações que nortearão, por exemplo, a criação de novos espaços de integração, a revisão dos eixos peatonais, a recuperação das áreas naturais ou, como almeja-se, todos estes simultaneamente.

Apesar das críticas ao uso demasiado das tecnologias como inibidor dos encontros presenciais, alguns autores direcionam seu olhar aos benefícios desta nova realidade, no sentido contrário às críticas. Townsend (2013) acredita na sobrevivência das cidades após a revolução digital e que cidades em todos os lugares estão florescendo porque novas tecnologias os tornam ainda mais valiosos e eficazes como lugares de reunião cara a cara. Para Ratti (2017), o design, a inovação e a tecnologia podem ser usados para melhorar a vida das pessoas, e as potencialidades do uso da rede internacional de computadores (internet) podem devolver às cidades seu valor de origem, de conectar as pessoas e trazer de volta sua natureza perdida.

Novamente, ao trazer ao contexto das universidades no século XXI, a tecnologia digital é parte natural da vida dos seus estudantes millenials, crescidos com a internet e com conectividade de fácil alcance (Chapman, 2006). Para atender a esta nova demanda de usuários, a universidade do futuro deverá funcionar de maneira híbrida, aliando o ensino tradicionalmente presencial com as novas ferramentas digitais. Além da relação comercial atrelada à difusão do conhecimento e da conexão urbana de longo alcance com as atividades remotas, para Zwaan (2017) já está claro que a Tecnologia da Informação e todas as formas de digitalização da comunicação e do conhecimento terão um grande impacto na ordem social e, por extensão, nas universidades e no mercado de trabalho.

A quantidade de dados disponiveis na Internet e a quantidade de dados que podemos processar usando computadores relativamente baratos e fáceis de acessar, estão levando a uma nova e imprevista forma de ciência. A exploração de big data é um campo surpreendentemente produtivo, no qual a análise de padrões em quantidades inimaginavelmente grandes de dados está dando origem a insights completamente novos (Zwaan, 2017 p. 108).

Apesar dessa aparente facilidade que a Tecnologia da Informação traz, o uso de dados de uma Instituição de Ensino Superior ainda possui barreiras que vão além da anonimização, seja pela baixa disponibilidade dos dados de infraestrutura (Hajrasouliha, 2017), seja pela pouca atualização dinâmica das informações da comunidade acadêmica (Zhou, 2016). Entretanto, o contexto de 2020 acelerou 0 enfraquecimento destas limitantes, demonstrando os potenciais do uso de banco de dados na gestão do espaço físico e na resiliência a eventos climáticos extremos, crises sanitárias ou dinâmicas de outras naturezas. Primeiro, pela necessidade de melhor conhecer as dinâmicas do capital humano que habita a universidade, em busca de soluções que evitem horários de pico, aglomerações no transporte coletivo e nos espaços acadêmicos de maior procura, como, por exemplo, o restaurante universitário. Em segundo, ao deslocar atividades para o modo não-presencial, se impulsiona a compreensão da universidade como um território inserido numa rede de centralidades urbanas, onde a produção do conhecimento, até então concentrada nos limites do campus, passa a estar diluída na residência de cada membro de sua comunidade.

\section{CONTEXTO LOCAL}

Imersa no meio urbano de Florianópolis, a Universidade Federal de Santa Catarina (UFSC) possui hoje em sua sede principal - o Campus Universitário Reitor João David Ferreira Lima (Campus Trindade) - mais de cem hectares de extensão. Caminhar e pedalar neste complexo territorial é desafio constante para milhares de pessoas e diversos são os motivos que levam a este desconforto. A 
precariedade da pavimentação e a inexistência de uma iluminação pública operam o óbvio, mas uma análise aprofundada pode demonstrar que o próprio campus foi alicerçado sobre uma inépcia de explorar as potencialidades de sua topografia natural plana e, mais recentemente, sua base de dados para compreender as dinâmicas de sua comunidade.

Desde que foi instalado na década de 1960 em uma fazenda a cerca de $5 \mathrm{~km}$ do centro histórico e comercial de Florianópolis, o Campus Trindade é um agente impulsionador do desenvolvimento urbano da região, hoje uma das suas principais centralidades. A partir de 2007, com a reestruturação das universidades brasileiras e a implantação de novos campi, a população da UFSC aumentou consideravelmente, acolhendo hoje mais de 50 mil membros distribuídos em diversas cidades de Santa Catarina, permanecendo, contudo, cerca de $90 \%$ deles na sede. Com o anseio recorrente pela proximidade entre moradia e local de estudo ou trabalho, a implantação da universidade levou a uma rápida densificação de seus arredores, revertendo em um impacto ambiental significativo nos locais onde se instala. A área construída da Bacia Hidrográfica do Rio do Meio, onde o Campus Trindade está inserido, cresceu de 24,43\% em 1998 para $39,52 \%$ em 2007, resultando nesse período um aumento de cerca de $26 \%$ no volume drenado pelo Rio do Meio (Mulungo, 2012). Assim, várias inundações nas últimas décadas impactaram o campus, causando perdas relevantes para a universidade. Enquanto os cursos d'água e suas margens agem como obstáculos para os pedestres, as largas vias asfaltadas que cortam o campus convidam os carros a se dispersarem por suas principais áreas, muitas delas transformadas em estacionamentos informais sobre as Áreas de Preservação Permanente, assim regidas pela Lei Federal n. 7803 (1989).

Apesar da potencialidade natural de favorecer o transporte ativo, visível na topografia predominantemente plana do campus e nos corredores verdes às margens dos córregos que o conectam aos bairros do entorno, os investimentos municipais seguem direcionados ao sistema viário para motorizados. Uma área de $33.170,12 \mathrm{~m}^{2}$ foi cedida em 2016 pela universidade para a ampliação do anel viário responsável pela ligação entre o centro comercial, o campus e as principais regiões da cidade. Quanto ao transporte coletivo, ainda que o campus e seu entorno tenham sido identificados em 2015 como principal polo de atração de viagens por motivo de estudo em Florianópolis, as linhas de ônibus movimentavam na região apenas 4.300 viagens diárias.

Este mesmo estudo apontou que, além da ausência do transporte público de qualidade como principal queixa de $53 \%$ dos que optam pelo carro em seu dia a dia, o tempo de viagem é o segundo motivador da escolha do modal entre os entrevistados (PLAMUS, 2015). Inseridas no Sistema Integrado de Mobilidade (SIM), rotas de ônibus conectam a universidade a todos os terminais de integração ativos no sistema, aos bairros do entorno e, com algumas linhas diretas, à região continental da cidade. Além de grande parte das linhas operar em baixa frequência, limitadas aos horários de pico, a falta de infraestrutura que priorize o transporte coletivo prejudica profundamente a fluidez do serviço, levando a sua baixa procura.
Em 2020, em pesquisa direcionada a toda comunidade da UFSC (Tabela 1), inclusive aos membros localizados em outros campi, enquanto o carro próprio segue como principal meio de transporte visado pelos servidores, tanto por $51,92 \%$ do técnicos-administrativos como por $72,61 \%$ dos docentes, para $39,72 \%$ dos estudantes que responderam à pesquisa o ônibus ainda é o modo de transporte mais utilizado. Contudo, um número expressivo de 7.600 pessoas manifestou a caminhada como principal meio de locomoção até o campus. Várias pesquisas semelhantes já haviam sido realizadas na universidade para mapear as dinâmicas de mobilidade de sua comunidade, mas pela primeira vez ela foi feita através de um sistema integrado de autenticação, o que levou a uma amostra bem acima das anteriores.

Tabela 1: Quantidade de usuários por modo de transporte em cada categoria em números absolutos e percentuais.

\begin{tabular}{|c|c|c|c|c|c|c|c|}
\hline \multicolumn{2}{|l|}{ Alunos } & \multicolumn{2}{|c|}{ Docentes } & \multicolumn{2}{|c|}{ Técnicos } & \multicolumn{2}{|l|}{ Total } \\
\hline \multicolumn{8}{|c|}{ Deslocamento a pé } \\
\hline 6972 & $30 \%$ & 356 & $14 \%$ & 272 & $14 \%$ & 7600 & $27 \%$ \\
\hline \multicolumn{8}{|c|}{ Moto ou bicicleta } \\
\hline 1626 & $7 \%$ & 111 & $4 \%$ & 159 & $8 \%$ & 1896 & $7 \%$ \\
\hline \multicolumn{8}{|c|}{ Ônibus municipal } \\
\hline 6754 & $29 \%$ & 132 & $5 \%$ & 304 & $15 \%$ & 7190 & $26 \%$ \\
\hline \multicolumn{8}{|c|}{ Ônibus intermunicipal } \\
\hline 2521 & $11 \%$ & 17 & $1 \%$ & 113 & $6 \%$ & 2651 & $10 \%$ \\
\hline \multicolumn{8}{|c|}{ Carona, transporte por aplicativo ou táxi } \\
\hline 996 & $4 \%$ & 72 & $3 \%$ & 41 & $2 \%$ & 1109 & $4 \%$ \\
\hline \multicolumn{8}{|c|}{ Carro próprio } \\
\hline 4169 & $18 \%$ & 1824 & $73 \%$ & 1028 & $52 \%$ & 7021 & $25 \%$ \\
\hline \multicolumn{8}{|l|}{ Outros } \\
\hline 311 & $1 \%$ & 0 & $0 \%$ & 63 & $3 \%$ & 374 & $1 \%$ \\
\hline
\end{tabular}

De acordo com as dimensões morfológicas estudadas por Hajrasouliha (2017), o campus "bem projetado" foi conceitualizado como um campus bem conectado, estruturado em um ambiente compacto misto entre o meio urbano e as áreas verdes. Nosso argumento é que as universidades devem ir além de atuar como atratores de estudantes e pesquisadores. Elas devem incorporar e transmitir a regeneração dos ecossistemas associados ao desenvolvimento social de toda a cidade. As universidades têm uma grande possibilidade de explorar a tecnologia em seu território e implementar ações diárias em espaços mais resilientes em diversas escalas.

\section{METODOLOGIA}

Para atingir seus objetivos, a pesquisa parte de um levantamento documental do cadastro do Campus Trindade, fazendo um sucinto censo demográfico da comunidade acadêmica integrado às diversas bases de dados abertos da universidade, seguido de um breve diagnóstico da situação encontrada em seu espaço físico. $\mathrm{Na}$ etapa posterior, uma análise técnica dos recursos e potencialidades de dois bancos de dados para a exploração das tecnologias de informação e comunicação e obtenção de aspectos da localização e movimentação da comunidade acadêmica. 
O primeiro desafio foi a atualização do banco de dados de endereços pela comunidade acadêmica - um cadastro único e pessoal vinculado a todos os sistemas de informação da universidade. Cada servidor ou aluno, ao ativar sua primeira matrícula, recebe uma identidade chamada IdUFSC que dá acesso aos sistemas de maneira integrada. Como o cadastro do endereço era feito unicamente ao ingressar na instituição, muitos estavam com a informação defasada. Com 46.525 endereços atualizados em 2019 a pedido da Reitoria para o desenvolvimento desta pesquisa, iniciou-se um trabalho integrado entre pesquisadores das áreas de Arquitetura e Urbanismo e Tecnologia da Informação para manipular estes dados de forma equilibrada, garantindo a máxima fidelidade das informações sem comprometer a privacidade dos indivíduos. Na UFSC, o gerenciamento de registros digitais é feito pela Superintendência de Governança Eletrônica e Tecnologia da Informação e Comunicação (SETIC), que armazena um grande banco de dados gerado constantemente ao longo de anos. Para sua disponibilização, esses dados, até então inexplorados, passam previamente por um processo de anonimização realizado pelo Laboratório de Segurança da Computação (LABSEC) do Departamento de Informática e Estatística (INE), através de técnicas de extração e limpeza de dados, para garantir a privacidade dos membros cadastrados, seguindo os critérios da Lei Geral de Proteção de Dados , excluindo possibilidades de identificação.

Somente após atender as exigências de anonimização, os dados são disponibilizados à equipe do Laboratório de Ecologia Urbana (LEUr) para a etapa de espacialização. Os Códigos Postais cadastrados foram agrupados a partir dos 5 primeiros dígitos e distribuídos no QGIS em rotas divididas em trechos de 5 minutos de caminhada (Figura 1), tornaram legível o mapeamento das dinâmicas da comunidade universitária na escala municipal. Os membros foram então divididos em dois grupos principais, ambos categorizados entre alunos, docentes e técnicos. Os que possuíam seus endereços cadastrados num raio de 10 minutos de caminhada contados a partir dos limites do campus, foram direcionados a estudos de transporte ativo, ou seja, deslocamento a pé ou bicicleta. A limitação deste raio foi definida considerando a extensão do território da universidade, que pode chegar a $2 \mathrm{~km}$ entre uma extremidade e outra, e as condições de trafegabilidade dada aos pedestres e ciclistas. Os demais membros, cujos Códigos Postais extrapolavam este raio, foram agrupados em regiões, simulando a conexão do campus com outras centralidades.

Além do banco de dados estático dos endereços residenciais, para o mapeamento das dinâmicas de acesso ao campus, foram obtidos ainda dados de conexão dos dispositivos móveis através dos pontos de acesso da rede sem fio (Wi-Fi), distribuídos por toda a universidade. Esta rede está vinculada ao serviço Eduroam, disponível para a comunidade acadêmica e científica internacional, onde, através da sua autenticação, o usuário pré-cadastrado acessa com segurança a internet de forma gratuita e automática, nas universidades do globo que oferecem essa cobertura. Assim como os dados de endereço, os dados de conexão de Wi-Fi também passaram pelo processo de anonimização pelo LABSEC antes de serem disponibilizados ao grupo de pesquisa em urbanismo. No estudo em questão, dispensou-se a compilação por categoria de vínculo (alunos, docentes ou técnicos), sendo solicitados os dados de horários do primeiro e último acesso agrupados por bairros residenciais. Uma amostra de 10.284 usuários da rede Wi-Fi com endereços cadastrados foi reduzida a 7.297 para garantir o anonimato, visto que grupos com menos de 5 membros foram descartados devido à possível identificação. Os demais foram agrupados em acessos ocorridos a cada 30 minutos registrados a partir das 6 horas da manhã.

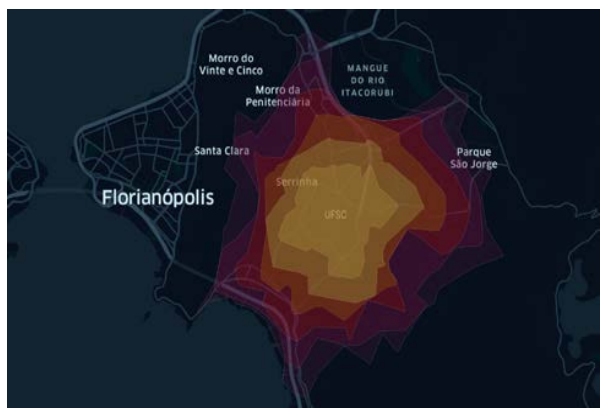

Figura 1 - Raios de caminhada a partir dos limites do campus em sequências dadas a cada 5 minutos.

\section{RESULTADOS}

Salvo o conhecimento empírico das especificidades de cada categoria de vínculo - como rotina de horários, faixa etária e poder aquisitivo - o primeiro passo foi complementar essas informações com um pequeno censo demográfico a partir da atualização dos endereços cadastrados pelo IdUFSC. Desta consulta, foi possível mapear os locais de origem residencial de cada grupo que busca o campus como destino diário. Na Tabela 2, distribuídos em quatro intervalos mensurados pelo tempo de caminhada até o limite do campus, pode-se perceber que a região do entorno imediato do campus (até 30 minutos de caminhada) é uma região bastante procurada como moradia por sua comunidade acadêmica, sendo que $17 \%$ do total da amostra dispõem da possibilidade de se deslocar ao campus a pé em trajetos de no máximo 10 minutos. Os grupos intermediários, entre 10 e 20 minutos (Grupo 2) e entre 20 e 30 minutos (Grupo 3) podem ser considerados com potencial para uso da bicicleta (Estudo 1) ou ainda em políticas de transporte coletivo que contemplem linhas rápidas de conexão ao campus (Estudo 2). O último grupo da Tabela 2 contempla o total de $74 \%$ de membros cujos Códigos Postais cadastrados ultrapassam trajetos de 30 minutos de caminhada, sendo eles direcionados ao incentivo ao transporte coletivo.

Tabela 2: Quantidade de membros por tempo de caminhada até o limite do campus.

\begin{tabular}{llll}
\hline Alunos & Docentes & Técnicos & Total \\
\hline
\end{tabular}

Grupo 1 - Até 10 min de caminhada do campus

$\begin{array}{llllllll}5144 & 17 \% & 443 & 17 \% & 374 & 14 \% & 5961 & 17 \%\end{array}$

Grupo 2 - Entre 10 e 20 min de caminhada

$\begin{array}{llllllll}1895 & 6 \% & 277 & 11 \% & 231 & 9 \% & 2403 & 7 \%\end{array}$

Grupo 3 - Entre 20 e 30 min de caminhada

$\begin{array}{lllllll}6754 & 29 \% & 132 & 5 \% & 304 & 15 \% & 7190 \quad 26 \%\end{array}$

Grupo 4 - Acima de 30 minutos de caminhada

$22656 \quad 75 \% \quad 1697 \quad 67 \% \quad 1919 \quad 74 \% \quad 26272 \quad 74 \%$ 


\section{ESTUDO 1 - TRANSPORTE ATIVO}

Tendo como amostra o Grupo 1 da Tabela 2, para o primeiro estudo foi feito um subagrupamento dos Códigos Postais entre os acessos existentes ou potenciais do campus, identificados de A a J. Com isso foi possível identificar os locais que serviriam como portais conectores entre o campus e a população do entorno. Nota-se, destes subagrupamentos mapeados na Figura 2, que as regiões representadas pelos acessos I, ao Norte, e E, ao Sul, são as de maior número de moradores, seguidos dos acessos $\mathrm{G}$ e $\mathrm{H}$, a Oeste, e $\mathrm{B}$, a Leste. Essas cinco áreas mais procuradas pelos membros para morar são os que possuem acessos formalizados junto ao campus.

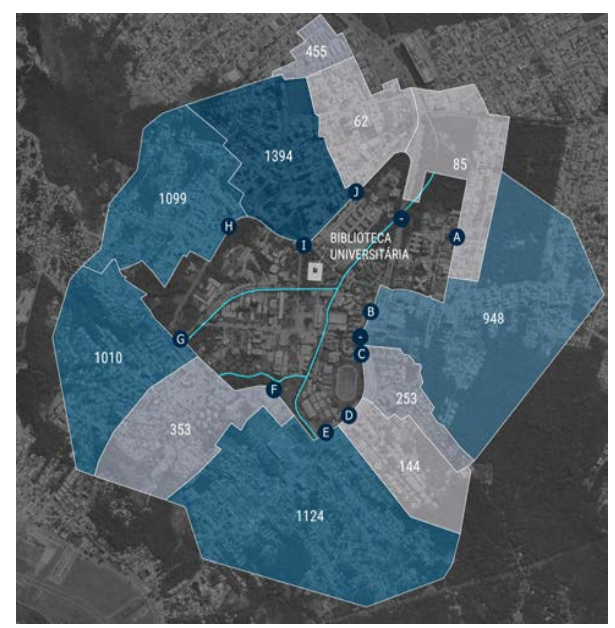

Figura 2: Subagrupamentos de moradores por acessos no raio de 10 minutos de caminhada.

Quanto à disposição dos acessos, cabe destacar ainda, a relação com os principais cursos d'água que atravessam o campus. O Rio do Meio e o Rio Carvoeira, cujas entradas no campus localizam-se respectivamente próximas aos acessos $E$ e $G$, se juntam próximo a Biblioteca Universitária e seguem no sentido nordeste em direção a uma das poucas regiões de vegetação densa preservada do campus. Além de ser um dos principais destinos dos estudantes, a Biblioteca Universitária é onde estão localizadas as duas principais áreas de embarque e desembarque de transporte coletivo no campus. Esse ponto central integrado aos corredores verdes que margeiam os cursos d'água, em boa parte ocupados por estacionamentos, possuem grande potencial de conexão do campus com a cidade.

A inexistência de alguns desses acessos leva a resultados como os vistos na Tabela 1, que, apesar de $33 \%$ dos professores morarem em raios cujo transporte ativo poderia ser incentivado (Grupos 1 a 3 da Tabela 2), somente $18 \%$ dos membros desta categoria utilizam o deslocamento a pé ou por bicicleta como principais meios de locomoção até a universidade. A precariedade dos acessos, calçadas e ciclovias indo ao encontro das facilidades promovidas pelas vias asfaltadas e da gratuidade de estacionamento, leva muitas pessoas a optarem por meios motorizados individuais em seus deslocamentos diários.

\section{ESTUDO 2 - TRANSPORTE COLETIVO}

Reconhecida a realidade do entorno do campus, onde as políticas de transporte ativo expressam maior potencialidade, o Estudo 2 parte de uma análise dos Códigos Postais em localidades onde a distância leva à necessidade do uso de motorizados. Separado o Grupo 1, representado na cor azul na Figura 3, os demais grupos foram distribuídos no mapa da Grande Florianópolis em regiões, sendo os que estão sob abrangência do transporte público municipal representados em amarelo e os localizados fora do município sede indicados em magenta, representando os potenciais usuários do transporte coletivo intermunicipal.

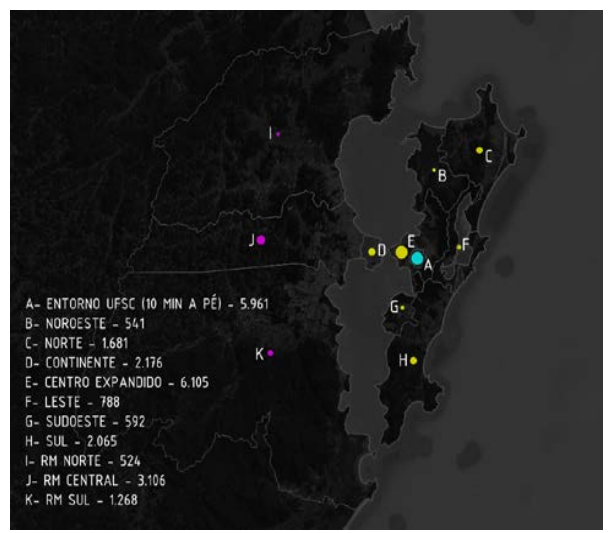

Figura 3: Subagrupamentos de moradores por regiões na Grande Florianópolis.

Como resultado já esperado, a região que engloba os bairros centrais de Florianópolis (Grupo E) é onde o maior número de membros do campus reside, totalizando 6.105 cadastros, seguido da região do entorno do campus (Grupo A), onde 5.961 estão no raio de 10 minutos de caminhada. O que surpreende no mapa é que a terceira região mais populosa não está em Florianópolis. Um grupo de 3.106 moradores da Região Metropolitana (RM) Central (Grupo J) se destina ao campus para estudar ou trabalhar, principalmente oriundos do município de São José.

Apesar do expressivo número de 4.898 membros da universidade que residem nas cidades vizinhas, não existem linhas intermunicipais que as conectem diretamente ao campus, tendo elas o Centro de Florianópolis como destino final. Ao chegar na ilha, os que optam pelo transporte coletivo são obrigados, assim, a pagar por uma nova passagem para seguir seu trajeto até a universidade, visto que os sistemas não são integrados entre os municípios da metrópole.

O aumento considerável no custo e tempo de deslocamento, somado à superlotação dada pela junção da demanda dos bairros do continente e do centro nas linhas que conectam o Terminal de Integração do Centro (TICEN) com a universidade, são apenas indícios do porquê de apenas 2.651 pessoas utilizarem o transporte intermunicipal na pesquisa de 2020 (Tabela 1).

Voltando aos limites de Florianópolis, na Figura 3 destacam-se os bairros do continente somando 2.176 
moradores e, na porção insular, as extremidades Sul e Norte, respectivamente com 2.065 e 1.681 membros da universidade em cada. A ausência de medidas que priorizem o transporte coletivo - como melhoria de infraestrutura, redução nas tarifas, aumento na disponibilidade de horários e itinerários e maior integração intermunicipal - e a gratuidade dos estacionamentos no campus são fortes atrativos ao uso dos automóveis particulares pela comunidade acadêmica.

\section{ESTUDO 3 - HORÁRIOS DE ACESSO}

Visando complementar as informações estáticas levantadas a partir dos endereços residenciais da comunidade acadêmica, o Estudo 3 resulta da análise das dinâmicas de horário de entrada e saída dos usuários no campus. Para tal, foi feito o cruzamento do banco de dados de cadastro pessoal (IdUFSC) com o de uso da rede Wi-Fi (Eduroam), obtendo os horários da primeira e última conexão agrupados por bairro de origem. Com isso, foi possível simular a performance da comunidade acadêmica nas principais vias de acesso ao campus, compreendendo as variações de demanda por deslocamento e transporte ao longo do dia.

A Figura 4 ilustra especificamente as dinâmicas de deslocamento de chegada, ou seja, no sentido residênciacampus, no intervalo entre $14 \mathrm{~h} 00$ e $14 \mathrm{~h} 30$. O total de primeiras conexões foi disposto em trechos que se juntam conforme vão convergindo vias principais dos bairros de origem aos eixos viários por onde passam as linhas de transporte coletivo. O número indicado em cada trecho é progressivo à medida que se aproxima do campus, representando o somatório dos potenciais usuários que estariam se deslocando naquele momento em direção à universidade.

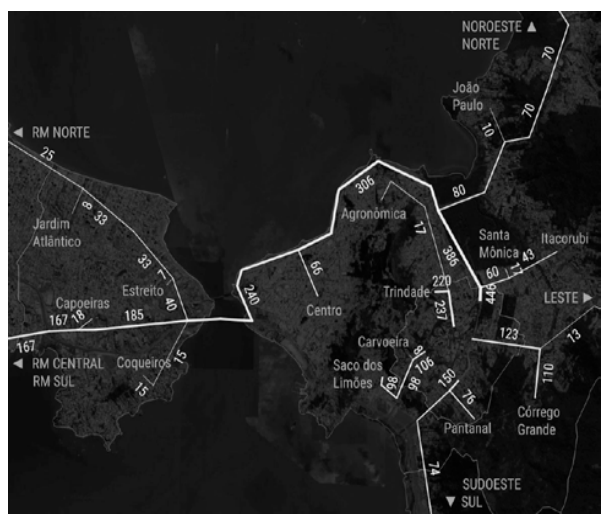

Figura 4: Quantitativo de conexões $14 \mathrm{~h} 00$ e $14 \mathrm{~h} 30$ por trecho.

Evidencia-se com o estudo a densidade da comunidade acadêmica nos principais eixos viários da Grande Florianópolis em determinados horários do dia. Nota-se também que alguns dos trechos que possuem maiores registros nesse intervalo de 30 minutos, não possuem linhas diretas ou faixas exclusivas que deem vazão à demanda. A compreensão destas dinâmicas pode orientar a elaboração de políticas de mobilidade que favoreçam o transporte coletivo para toda a população.

\section{DISCUSSÃO}

A Grande Florianópolis, recém promovida a Metrópole pelo Instituto Brasileiro de Geografia e Estatística (IBGE), está inserida em um contexto estadual específico - uma rede bem-encadeada de instituições públicas descentralizadas, com grande dinamismo econômico e a menor média nacional para deslocamento até uma Instituição de Ensino Superior (IBGE, 2020). Na escala local, além da presença da UFSC que por seis décadas vem cativando novos residentes, fatores como a notória qualidade de vida promovida pela paisagem natural remanescente e o reconhecimento nacional como polo atrativo em tecnologia, nutrem Florianópolis como a cidade ideal para um campus completo, assim definido por Hajrasouliha (2017) como sendo um local conveniente para morar, trabalhar, socializar e aprender.

Enquanto para alguns o campus universitário estava sob ameaça de desaparecimento dado o aumento significativo da tecnologia do ensino a distância, Zwaan (2017) apontava os benefícios de se estudar em comunidade, onde a interação presencial, principalmente nos anos iniciais da vida acadêmica, reforça a atuação dos professores como guias na jornada de seus jovens alunos. Protagonista da Greve Geral pelo Clima (\#ClimateStrike) em setembro de 2019, esta geração sedenta por mudanças compreende a força de sua performance no mundo para além dos limites de suas residências, e vê no campus universitário o palco que melhor deve representar seus ensaios para o futuro.

Nosso papel hoje não é fornecer a solução; é fornecer diferentes possibilidades para o futuro. No século 21 , as mudanças devem ser um ato coletivo. E a tecnologia nos permitirá chegar lá e construir uma estrutura que permita o desenvolvimento de um código aberto e a participação dos cidadãos (Ratti, 2017).

Apesar da forçosa eclosão das ferramentas digitais em 2020, o esvaziamento dos campi manifestou nos acadêmicos a lacuna deixada pela falta do convívio diário, o debate cara a cara e a orientação essencial nas diversas etapas da produção do conhecimento. Em um cenário de equilíbrio entre as perspectivas apresentadas no referencial teórico e a realidade imposta pela crise sanitária da COVID-19, os gestores da universidade e municipais terão a oportunidade de estabelecer um plano conjunto de reformulação do espaço pedagógico que se almeja para abrigar as gerações futuras, ambientalmente engajada e socialmente justa. Por meio de políticas de gerenciamento de transporte destinadas a reduzir a demanda por estacionamento, o valor da terra é devolvido para o suporte do aprendizado e para a restauração da paisagem do campus (Chapman, 2006).

Cabe à universidade, contudo, promover soluções que atendam essa expectativa, harmonizando seu desenho urbano à cidade onde está instalada. Os três estudos apresentados identificam diferentes problemas que, a partir de soluções integradas entre a gestão da universidade e municipal, podem inibir o tráfego de motorizados individuais, potencializar o uso de transporte ativo e regenerar a qualidade paisagística da UFSC. A construção de eixos peatonais, com ciclovias e novos acessos que transpassam os limites do campus e aproximam a comunidade aos recursos naturais; a criação de novos itinerários de transporte coletivo que conectem 
às centralidades residenciais, reduzindo distâncias, tempo e custos de deslocamento; a ampliação conjunta dos horários das linhas de ônibus, pela prefeitura, e das atividades acadêmicas, pela universidade, diluindo as demandas por transporte ao longo do dia, são exemplos de soluções indicadas pela interpretação das dinâmicas humanas através dos bancos de dados.

Seja visando o campus sustentável (Chapman, 2006), conectado (Hajrasouliha, 2017) ou a universidade híbrida do futuro (Zwaan, 2017), o presente artigo buscou apoiar, através do uso de banco de dados, a criação de políticas de mobilidade urbana que atraiam as pessoas a presença física e a se reconectar com os recursos naturais a sua volta. A requalificação das áreas verdes resgata o conceito de campus universitário como um grande espaço público de intercâmbio de experiências, mudando paradigmas do seu uso de dentro para fora, transportando às inúmeras centralidades integradas a sua rede de pessoas a realidade que se almeja como futuro.

\section{AGRADECIMENTOS}

Agradecemos ao Conselho Nacional de Desenvolvimento Científico e Tecnológico (CNPq), ao Laboratório de Segurança em Computação (LabSEC/UFSC) e à Superintendência de Governança Eletrônica e Tecnologia da Informação e Comunicação (SeTIC/ UFSC).

\section{REFERÊNCIAS}

Brasil. (2018). Lei n. 13.079, de 14 de agosto de 2018. Lei Geral de Proteção de Dados Pessoais (LGPD). Diário Oficial da União.

Chapman, M. P. (2006). American places: In Search of the Twenty-first Century campus. Westport, CT: Praeger.

D'Acci, L. (2019). A new type of cities for liveable futures. Isobenefit Urbanism morphogenesis. Journal of Environmental Management. Disponível em: doi.org/10.1016/j.jenvman.2019.05.129

Grimm, N. B., Faeth, S. H., Golubiewski, N. E., Redman, C. L., Wu, J., Bai, X., \& Briggs, J. M. (2008). Global change and the ecology of cities. Science. Disponivel em: doi.org/10.1126/science.1150195

Hajrasouliha, A. (2017). Campus score: Measuring university campus qualities. Landscape and Urban Planning. Disponível em: doi.org/10.1016/j.landurbplan.2016.10.007
Instituto Brasileiro de Geografia e Estatística. (2020). Regiões de influência das cidades: 2018. Rio de Janeiro. Disponível em: biblioteca.ibge.gov.br/index.php/bibliotecacatalogo? view $=$ detalhes $\&$ id $=2101728$

IBOPE Inteligência. (2020). Pesquisa de Opinião Pública: Viver em São Paulo: Pandemia. Disponivel em: www.ibopeinteligencia.com/arquivos/200181-

2_ESPECIAL\%20PANDEMIA_2_Aprese\%20Final\%20Nova \%20Capa.pdf

Lei n. 7.803, e 18 de julho de 1989 (1989). Dispõe sobre o Código Florestal Braileiro. Diário Oficial da União. Brasília, DF: Casa Civil.

Morozov, E., \& Bria, F. (2018). Rethinking the smart city: Democratizing Urban Technology. New York: Rosa Luxemburg Foundation.

Mulungo HE. Estudo de inundação na bacia do campus da UFSC Florianópolis, Brazil: Universidade Federal de Santa Catarina, 2012.

Ratti, C. (2017). Data Driven. Entrevista concedida a Susan Nerberg, Azure Magazine. Disponível em: www.azuremagazine.com/article/carlo-ratti-data-designcities-future/

Santa Catarina. (2015). Plano de Mobilidade Urbana Sustentável da Grande Florianópolis - Relatório Final - Consolidação das Propostas e Plano de Implementação. Florianópolis.

Sedlacek, S. (2013). The role of universities in fostering sustainable development at the regional level. Journal of Cleaner Production. Disponível em: doi.org/10.1016/j.jclepro.2013.01.029

Taylor, I. (2016). Future Campus: Design Quality in University Buildings. RIBA Publishing.

Townsend, A. (2013). SmartCities: Big Data, civic hackers, and the quest for a new utopia. New York, NY: W. W. Norton \& Company.

Zhou, J. (2016). Proactive sustainable university transportation: Marginal effects, intrinsic values, and university students' mode choice. International Journal of Sustainable Transportation. Disponivel em: doi.org/10.1080/15568318.2016.1159357

Zwaan. (2017). Higher Education in 2040. A Global Approach. Amsterdam University Press.

Warekar, R; Patil, S. (2014) Efficient Approach for Anonymizing Tree Structured Dataset using Improved Greedy Search Algorithm. International Journal of Science and Research (IJSR). Disponível em: doi.org/10.21275/v4i12.nov152111

Westin, A. F.; Ruebhausen, O. M. (1967). Privacy and Freedom. [S.L.]: New York: Atheneum. 